institutional history. In it he sets out, with characteristic objectivity, the various developments in the British organisation of medical research and the administrative lessons to be learned from these. As such its relevance extends beyond the sphere of its immediate subject to a central problem of the scientific and technological age in which we are now living; namely, that of providing, not only for the development of scientific knowledge, but also for its integration into the machinery of government.

Like his old schoolfellow, Wilson Jameson, the architect of the National Health Service, Thomson understood that for any human institution to be a success, it must satisfy both of two fundamental requirements. It must be in conformity with the realities of that it seeks to organise. It must equally be in conformity with the deeply held sentiments of those who have to make it work. In his own time, Landsborough Thomson contributed his quota to realising these conditions and, thereby, to creating the institutions required if activities that depend on acts of individual judgment are to be integrated into the structure of social organisation. That was the deeper significance of his life's work and his essential legacy to future generations.

Harold Himsworth

\section{Meirion Thomas}

MEIRION Thomas who died in his eighty-third year on 5 April 1977 at Tywyn in his native Wales will be remembered not only for his academic and athletic prowess but also for sterling personal attributes.

Born in North Wales in 1894, his early academic career as a student of University College of North Wales was interrupted when he was commissioned in the South Wales Borderers in 1914 and later transferred to the Special Companies Division of the Royal Engineers. On demobilisation in 1919 he went to Cambridge (Trinity Hall) where, inspired by his contacts with Gowland Hopkins, F. F. Blackman and Muriel Onslow, among others, he developed interests in plant physiology and biochemistry. He joined the Botany Department in the Newcastle division of Durham University as a lecturer in 1924, became Reader in Plant Physiology in 1942, and in 1946 Professor and Head of the Department where he remained until retirement in 1961.

His book Plant Physiology, first published in 1935, brought him to the fore because of its new approach to the subject with its emphasis on the experimental study of plant metabolism. It was reprinted and revised periodically to a fifth edition in 1973 , always re- taining his aim of educating students in the development of ideas and investigation rather than simply presenting the present state of knowledge. His main research interests as covered by his own publications embraced various aspects of respiratory and acid metabolism with occasional ventures into other fields e.g. melanism, but the sum total of his contributions to science and life could only be assessed by perusal of the long list of students, colleagues and friends who would readily attest that whatever they have achieved, and some have achieved great distinction, they owe much to their contacts at some stage with him.

Meirion Thomas's eminence in science was marked by his election to the Royal Society in 1949. Two other distinctions which gave him great pleasure, and of which he was justifiably proud, were the award of the Charles Reed Barnes Honorary LifeMembership of the American Society of Plant Physiologists in 1963, and the Honorary Degree of D.Sc. of the University of Wales in 1964.

At Cambridge he won a soccer blue and played cricket, being elected to the Crusaders Club in 1923. He continued enthusiastic participation in both with Northern clubs for many years and remained actively interested in them throughout his life. A few years after retirement, his love of Wales, its language, and its cultures drew him to Tywyn, but not as a recluse. He maintained contacts with all his friends, continued to attend scientific meetings and enjoy a full life. He will be remembered with respect and great affection by all who knew him.

$$
\text { S. L. Ranson }
$$

\section{A. V. Nikolaev}

ACAdemician Anatolii Vasil'evich Nikolaev, a leading Soviet expert in geochemistry and the utilisation of natural resources died on February 13, 1977.

Nikolaev was born in 1902. He graduated from the University of Leningrad in 1924, and soon afterwards became involved in the problems of resource utilisation. From 1927 to 1931 he was head of the Pavlodar Salt Expedition of the Commission to Study Production Resources of the Academy of Sciences of the USSR, and from 1931 to 1935 he headed a similar, combined, expedition to the Kulunda area. Between 1934 and 1957 he worked at the Institute of General and Inorganic Chemistry of the Academy of Sciences in the USSR, and, simultaneously, held various teaching posts in Moscow, at the Polygraphic Institute and the Institute of Non-Ferrous Metals and Gold, becoming a Professor at the latter Institute in 1946. In 1957 he moved to Novosibirsk, to become Director of the Institute of Inorganic Chemistry of the Siberian Branch of the Academy of Sciences of the USSR. The following year he was elected a Corresponding-Member of the Academy of Sciences and a Praesidium Member of the Siberian Branch. He became a full member of the Academy in 1966.

Nikolaev's main works deal with the physical and chemical analysis of salt systems, thermography and radiochemistry. His interests were wide and his published titles reflect this diversity, ranging from The Kulunda Salt Lakes and means of desalinating them and The physico-chemical study of natural resources, to Protection against radioactivity, and $A$ study of the processes of oxidation of complex compounds of divalent platinum.

In 1947, he won the Vernadskii prize, and, in 1967, on the occasion of his 65 th birthday, he was awarded the Order of Lenin.

Vera Rich

\section{W. F. McClare}

Colin W. F. McClare, lecturer in biophysics at King's College London, died on 4 January 1977 at the age of 39 .

$\mathrm{He}$ won an open Exhibition to Emmanuel College Cambridge from Felsted School in 1955 and read Natural Sciences, specialising in chemistry. His interest in applying chemical concepts to biological problems was already apparent in his $\mathrm{PhD}$ project on free radicals in biology and was developed further when as a Beit Fellow he studied energy transfer in nucleic acids.

After his appointment at King's College in 1963, he turned his attention to fundamental problems in bioenergetics, especially muscle contraction. $\mathrm{He}$ stressed the importance of time scales in thermodynamics and proposed a muscle model employing stimulated resonant energy transfer. He strongly advocated that the secret of ATP lies in the molecular details of its hydrolysis and not simply in its overall free energy change.

Colin was a person of great enthusiasm and intensity of thought. His interests ranged from practical methods of analytical biochemistry to the social and philosophical implications of science. His search for excellence and his competitive spirit showed in his love of discussion and in his sporting activities. As a teacher, he inspired his students through an outstanding ability to make ideas come to life.

$\mathrm{He}$ is survived by his wife Gill. His stimulating and ever-helpful presence will be missed by his many friends.

W. R. Lieb

I. Gonda 